\title{
Meredith B. MCGUIRE, Lived Religion. Faith and Practice in Everyday Life
}

New York, Oxford University Press, 2008, 304 p.

\section{Géraldine Mossière}

\section{CpenEdition}

Journals

Édition électronique

URL : http://journals.openedition.org/assr/21167

DOI : $10.4000 /$ assr.21167

ISSN : 1777-5825

Éditeur

Éditions de l'EHESS

Édition imprimée

Date de publication : 31 décembre 2009

Pagination : $75-342$

ISBN : 978-2-7132-2218-4

ISSN : 0335-5985

Référence électronique

Géraldine Mossière, "Meredith B. mcGuIRE, Lived Religion. Faith and Practice in Everyday Life », Archives de sciences sociales des religions [En ligne], 148 | octobre-décembre 2009, document 148-90, mis en ligne le 03 juin 2009, consulté le 21 septembre 2020. URL : http://journals.openedition.org/assr/21167 ; DOI : https://doi.org/10.4000/assr.21167

Ce document a été généré automatiquement le 21 septembre 2020.

(C) Archives de sciences sociales des religions 


\title{
Meredith B. MCGUIRE, Lived Religion. Faith and Practice in Everyday Life
}

New York, Oxford University Press, 2008, 304 p.

\author{
Géraldine Mossière
}

\section{RÉFÉRENCE}

Meredith McGuire, Lived Religion. Faith and Practice in Everyday Life, New York, Oxford University Press, 2008, 304 p.

1 Meredith McGuire est professeur de sociologie de la religion à Trinity University dans le sud des États-Unis. Se qualifiant elle-même de «Quaker » pratiquante, ses travaux sont axés sur la religiosité dans les sociétés occidentales, et en particulier sur les liens entre religion et guérison dans les pratiques religieuses de ses compatriotes. À cet égard, elle est l'une des premières dans sa discipline à avoir insisté sur le rôle du corps dans le religieux, en proposant de lier corps, émotion et esprit dans toute approche du social.

2 L'accent ainsi porté sur l'individu et le vécu ne fait pas défaut dans son dernier ouvrage où, reprenant la critique de Talal Asad, elle défie les outils conceptuels euro-centriques et historiquement construits, définissant la religion comme un ensemble de pratiques et de croyances unitaire, défini dans un cadre organisationnel et relativement stable. En s'intéressant aux comportements religieux individuels contemporains, son étude vise à saisir la complexité, les incohérences apparentes, l'hétérogénéité, ainsi que la gamme des pratiques que les individus s'approprient et combinent en des amalgames originaux, et porteurs de sens pour eux-mêmes. S'inspirant d'une sémantique phénoménologique, l'anthropologue développe ainsi la notion de "lived religion » (religion vécue), un concept relativement opérationnel qui lui permet de distinguer l'expérience réelle des formes de religiosité prescrites par les croyances et pratiques institutionnalisées. Ainsi, le champ des « religions vécues » propose un espace subjectif et potentiellement très créateur pour l'expression du religieux. 
3 La richesse de l'ouvrage réside probablement dans la profondeur de la démonstration qui s'appuie sur de nombreux exemples réunis grâce à la longue expérience de terrain de l'auteur, tant auprès des chrétiens évangéliques blancs du sud des États-Unis que des populations immigrantes d'origine latino, mais aussi par une solide documentation ethno-historique sur le christianisme. M. McGuire débute par une généalogie de la sociologie de la religion dont elle souligne les biais épistémologiques et l'incapacité à capter les preuves empiriques des expressions populaires du religieux. Discutant ensuite l'articulation des religiosités actuelles autour du motif de la guérison et de la construction d'identités "genrées" (gendered), l'auteur s'attache à démontrer le lien entre spiritualité et matérialité à travers le rôle du corps conçu dans une perspective holistique : le religieux est incorporé. Car si la religion vécue repose sur des pratiques qui inscrivent le quotidien dans un récit du soi normé (code alimentaire, vestimentaire, sexuel, etc.), celles-ci se matérialisent par le corps et les sens, et leur restructuration rituelle dans le temps et dans l'espace. À cet égard, l'auteur offre un examen particulièrement intéressant $d u$ développement historique de pratiques religieuses "genrées" qu'elle associe aux changements sociaux. Dans le contexte actuel où la répartition traditionnelle des rôles et devoirs est remise en question par une diversité culturelle de plus en plus grande, les mouvements religieux proposent de nouvelles pratiques spirituelles qui transforment les corps et les émotions, et construisent des identités et rapports sociaux qui transcendent les frontières habituelles délimitant les notions de race, de classe sociale et du genre. Par exemple, les groupes chrétiens conservateurs attribuent aux femmes le rôle de gardienne du foyer, ultime bastion de stabilité dans un monde vu comme chaotique et dangereux. Si ces dernières adoptent l'identité féminine transmise par une telle «idéologie de la domesticité », c'est parce que tout en limitant leur sphère d'influence, elle élève également leur statut dans l'espace familial.

4 L'auteur mentionne que la religion vécue ne participe pas uniquement de la subjectivité des individus et qu'elle se construit en communauté. Toutefois, on peut regretter que l'ouvrage se concentre essentiellement sur les religiosités individuelles, omettant ainsi le rôle des communitas contemporaines, où des expériences intersubjectives vécues collectivement façonnent et orientent les trajectoires personnelles. L'emphase portée sur l'individu l'empêche par ailleurs de traiter des nouvelles solidarités communautaires et dynamiques religieuses transnationales (la Oummah musulmane par exemple) qui inscrivent l'individu au sein de systèmes caractérisés par des définitions alternatives de l'individu et de son articulation avec le social.

5 En conclusion, outre l'intérêt ethnographique considérable de l'ouvrage, le concept de « religion vécue » qu'il introduit ouvre de nouvelles perspectives de recherche sur la fluidité des pratiques religieuses contemporaines, dans un monde lui-même en mouvance. L'auteur propose, en effet, de repenser les notions de tradition et d'identité religieuse, ainsi que la sémantique plus récente de l'hybridité et du mélange (syncrétisme, bricolage, créolisation, etc.) Alors que le souci d'authenticité des rituels a historiquement légitimé le mythe fondateur et assuré la cohésion sociale du groupe, l'actuelle remise en question des catégories et des symboles, ainsi que les échanges et la créativité culturels motivent la mobilité des identités et des appartenances. S'il ne participe pas d'organisations religieuses actives, le sujet croyant n'en est pas moins engagé pour autant, en attestent l'expression de sa foi et les manifestations de sa pratique, dans le privé comme sur la place publique. 